\title{
Analisis Daya dan Biaya Penggunaan Low Sulfur Fuel Oil (LSFO) dengan High Sulfur Fuel Oil (HSFO) dilengkapi Scrubber pada Kapal Niaga
}

\author{
Bambang Wahyudi ${ }^{*}$, Imam Fahcruddin ${ }^{b}$

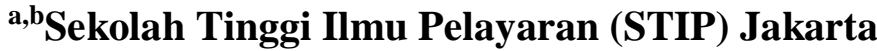 \\ aEmail: bambangwahyudi23@gmail.com \\ bEmail: fahrudinuin@gmail.com
}

\begin{abstract}
ABSTRAK
Berdasarkan Marine Pollution (MARPOL) Convention Annex VI Regulasi 14, kapal niaga wajib menggunakan BBM bersulfur rendah (Low Sulfur Fuel Oil - LSFO) dengan kandungan sulfur dibawah 0,5\% atau tetap memakai bahan bakar berat (High Sulfur Fuel Oil HSFO) dengan kandungan sulfur diatas 0,5\% tetapi wajib memasang exhaust gas cleaning system atau scrubber. Indonesia masuk dalam Negara anggota International Maritime Organization (IMO) sehingga harus mematuhi aturan tersebut. Penelitian ini bertujuan untuk menganalisis penggunaan bahan bakar dengan kandungan sulfur dibawah 0,5\% atau diatas $0,5 \%$ berdasarkan daya serta biaya yang ditimbulkan guna tetap memenuhi aturan Marpol Convention Annex VI Regulasi 14. Teknik analisis data yang digunakan dalam penelitian ini untuk daya menggunakan rumus Dulong, kemudian untuk biaya ditinjau dari perbandingan pembelian HSFO dengan LSFO disertai biaya pembelian dan instalasi scrubber. Berdasarkan hasil penelitian diperoleh kesimpulan bahwa daya yang dihasilkan HSFO lebih besar daripada LSFO dengan rasio 1,15. Kemudian, shipowner akan mendapat keuntungan yang lebih banyak apabila melakukan investasi pembelian dan instalasi scrubber pada kapal-kapal mereka daripada mengganti bahan bakar yang semula HSFO dengan LSFO.
\end{abstract}

Kata Kunci: bahan bakar kapal, sulfur, scrubber, Marpol

\section{PENDAHULUAN}

Salah satu kontributor polutan konvensional dan gas rumah kaca (GRK) sektor transportasi adalah dari sektor transportasi laut. Menurut perkiraan, sektor transportasi laut menyumbang emisi GRK sebesar 3\% (Helfre et al, 2013). Selain itu, emisi dari kapal yang sedang dalam proses docking di pelabuhan mencapai 10 kali dari emisi operasi pelabuhan itu sendiri (Habibi \& Rehmatulla, 2009). Untuk itu reduksi emisi dari sektor transportasi laut menjadi penting untuk dilakukan (Sukmanofith, 2019).
Beberapa kajian terkait mitigasi emisi di sektor transportasi laut menunjukkan bahwa strategi mereduksi emisi dapat diiringi dengan efesiensi energi baik secara murah (at no cost) bahkan mendapatkan keuntungan (Faber et al., 2009; Buhaug et al, 2009). Pada umunya, kajian terkait emisi sektor transportasi laut terbagi atas dua kategori yaitu: kajian yang mengestimasi potensi reduksi emisi $\mathrm{CO} 2$ dari sektor transport laut global (Buhaug et al., 2009; Alvik et al., 2010) ataupun kajian terkait aksi mitigasi emisi sektor transportasi laut (Gilbert et al., 2014). 
Di tengah dorongan yang lebih luas ke arah pasar energi yang lebih bersih, IMO mengatur untuk melarang kapal - kapal menggunakan bahan bakar dengan kandungan sulfur lebih tinggi dari $0,5 \%$. Hal ini diatur dalam aturan Marine Pollution (MARPOL) Annex VI Regulasi 14 mengenai Sulphur Oxides (SOx) and Particulate Matter. Mulai tanggal 1 Januari 2020, kapal-kapal yang melanggar aturan MARPOL Annex VI Regulasi 14 dapat disita atau ditahan oleh petugas Port State Control di luar negeri.

Untuk mendukung aturan tersebut, Indonesia melalui Kementerian Perhubungan telah menerbitkan Peraturan Menteri Perhubungan Nomor PM 29 Tahun 2014 yang mana pada pasal 36 mengatur tentang batasan kandungan sulfur pada bahan bakar di kapal sebesar $0,5 \%$ dimulai per tanggal 1 Januari 2020. Kemudian, Direktur Jenderal Perhubungan Laut telah menerbitkan Surat Edaran Nomor UM.003/93/14/DJPL-18 tanggal 30 Oktober 2018 tentang Batasan Kandungan Sulfur Pada Bahan Bakar dan Kewajiban Penyampaian Konsumsi Bahan Bakar di Kapal. Lebih lanjut, Direktur Jenderal Perhubungan Laut telah menerbitkan Surat Edaran Nomor UM.003/1/2/DK-19 tentang penyampaian hasil sidang Komite Perlindungan Lingkungan Perairan (Marine Environment Protection Commitee) ke 73 di Kantor Pusat IMO London yang ditujukan kepada seluruh Unit Pelaksana Teknis Ditjen Hubla dan stakeholder.

Saat ini, jumlah produksi bahan bakar jenis Marine Fuel Oil (MFO) 180 yang selama ini diproduksi oleh RU IV Cilacap sebesar 1,9 juta KL/tahun (1030 ribu barel/bulan) masih banyak dan tetap digunakan untuk pelayaran nasional. MFO merupakan bahan bakar dengan kandungan sulfur mencapai $3,5 \% \mathrm{~m} / \mathrm{m}$ sehingga masuk dalam kategori High Sulfur Fuel Oil (HSFO) (Sudiono, 2019). https://10.46484/db.v1i1.179
Penggunan bahan bakar MFO berpotensi melanggar aturan MARPOL Annex VI Regulasi 14.

Terdapat tiga cara bagi kapal untuk memenuhi IMO Global Sulphur Cap $0.5 \%$. Yang Pertama adalah menggunakan bahan bakar LNG atau bahan bakar cair bertitik nyala rendah (Low Flashpoint Fuel) seperti methanol. Untuk LNG dan methanol, IMO sudah menyediakan regulasinya dalam IGF code (International Code for Ships using Gases and other Low Flashpoint Fuels), yang diadopsi pada tahun 2015. Dalam penggunaan LNG sebagai bahan bakar kapal, diperlukan instalasi dan permesinan bantu dalam kapal dengan biaya yang besar. Lebih lanjut, pengetahuan dan kompetensi kru kapal sangat dibutuhkan untuk menunjang kelancaran dalam pengoperasian kapal berbahan bakar LNG.

Cara kedua adalah beralih ke BBM yang berkadar low sulphur fuel di bawah 0.5\%. Low Sulphur Fuel seperti MGO (Marine Gas Oil) atau Distilate fuel selain harganya yang lebih mahal, ketersediaannya juga diragukan oleh pihak pelayaran. Tidak banyak refinery (produsen BBM) yang memproduksi MGO dengan tetap menjaga keekonomian bisnisnya (Simanjuntak, 2019 ).

Cara ketiga adalah dengan menggunakan scrubber. Pemasangan sistem Scrubber pada kapal dengan bahan bakar high sulfur fuel oil (HSFO) berpotensi untuk mereduksi polusi laut. Penelitian ini mengkaji tentang perbandingan penggunaan HSFO yang dilengkapi scrubber pada permesinan kapal dengan penggunaan low sulfur fuel oil (LHSFO) ditinjau dari biaya dan daya bahan bakar yang dihasilkan.

\section{METODE}

Adapun kerangka pemikiran yang digunakan dalam penelitian ini disajikan dalam gambar berikut: 


\begin{tabular}{|c|l|}
\hline Simbol & \multicolumn{1}{c|}{ Keterangan } \\
\hline $\mathrm{HHV}$ & Nilai kalor atas $(\mathrm{kJ} / \mathrm{kg})$ \\
\hline $\mathrm{T}_{1}$ & $\begin{array}{l}\text { Temperature air pendingin } \\
\text { sebelum penyalaan }\left({ }^{\circ} \mathrm{C}\right)\end{array}$ \\
\hline $\mathrm{T}_{2}$ & $\begin{array}{l}\text { Temperature air pendingin } \\
\text { sesudah penyalaan }\left({ }^{\circ} \mathrm{C}\right)\end{array}$ \\
\hline $\mathrm{C}_{\mathrm{V}}$ & $\begin{array}{l}\text { Panas jenis bom Kalorimeter } \\
\left(73259,6 \mathrm{~kJ} / \mathrm{kg}^{\circ} \mathrm{C}\right)\end{array}$ \\
\hline $\mathrm{T}_{\mathrm{kp}}$ & $\begin{array}{l}\text { Kenaikan temperature akibat } \\
\text { kawat penyala }\left(0,005^{\circ} \mathrm{C}\right)\end{array}$ \\
\hline
\end{tabular}

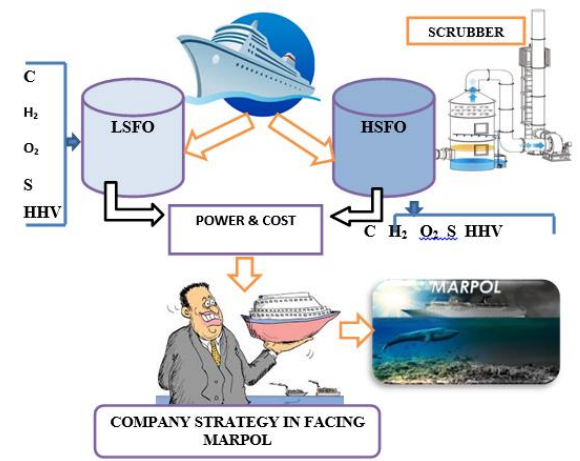

Gambar 1. Kerangka Pemikiran

Analisis penggunaan low sulfur fuel oil (LSFO) dengan high sulfur fuel oil (HSFO) dilengkapi scrubber pada kapal ditinjau pada aspek daya dan biaya. Penentuan daya dengan menggunakan rumus Dulong, kemudian untuk biaya ditinjau dari perbandingan pembelian HSFO dengan LSFO disertai biaya pembelian dan instalasi scrubber.

Reaksi kimia antar bahan bakar dengan oksigen dari udara menghasilkan kalor. Besarnya kalor yang ditimbulkan jika satu satuan bahan bakar dibakar sempurna disebut nilai kalor bahan bakar. Berdasarkan asumsi ikut tidaknya kalor laten pengembunan uap dihitung sebagai bagian dari nilai kalor suatu bahan bakar, maka nilai kalor bahan bakar dapat dibedakan menjadi nilai kalor atas atau nilai kalor bawah.

Nilai kalor atas (High Heating Value, HHV) merupakan nilai kalor yang diperoleh secara eksperimen dengan menggunakan bom kalorimeter dimana hasil pembakaran bahan bakar didinginkan sampai suhu kamar sehingga sebagian besar uap air yang terbentuk dari pembakaran hidrogen mengembun dan melepaskan kalor latennya. Data yang diperoleh dari hasil pengujian bom kalorimeter adalah temperatur air pendingin sebelum dan sesudah penyalaan. Selanjutnya untuk menghitung nilai kalor menggunakan persamaan sebagai berikut (Napitulu, 2006):

$$
H H V=\left(T_{2}-T_{1}-T_{k p}\right) C_{v}
$$

Tabel 1. Parameter Persamaan 1

Selain itu, dengan mengambil nilai parameter kalor pada sampel, besarnya nilai kalor HHV dapat ditentukan dengan persamaan berikut:

$$
\begin{array}{rl}
H H V=33950 & C \\
& +144200\left(H_{2}-\frac{O^{2}}{8}\right) \\
& +9400 S \quad \ldots(2)
\end{array}
$$

Tabel 2. Parameter Persamaan 2

\begin{tabular}{|c|l|}
\hline Simbol & \multicolumn{1}{|c|}{ Keterangan } \\
\hline $\mathrm{C}$ & $\begin{array}{l}\text { Presentase karbon dalam bahan } \\
\text { bakar }\end{array}$ \\
\hline $\mathrm{H}_{2}$ & $\begin{array}{l}\text { Presentasi hidrogen dalam bahan } \\
\text { bakar }\end{array}$ \\
\hline $\mathrm{O}_{2}$ & $\begin{array}{l}\text { Presentasi oksigen dalam bahan } \\
\text { bakar }\end{array}$ \\
\hline $\mathrm{S}$ & $\begin{array}{l}\text { Presentasi sulfur dalam bahan } \\
\text { bakar }\end{array}$ \\
\hline $\mathrm{M}$ & $\begin{array}{l}\text { Presentasi kandungan air didalam } \\
\text { bahan bakar (moisture) }\end{array}$ \\
\hline
\end{tabular}

Nilai kalor bawah (Low Heating Value, LHV) merupakan nilai kalor bahan bakar tanpa panas laten yang berasal dari pengembunan uap air. Umumnya kandungan hidrogen dalam bahan bakar cair berkisar 15\% yang berarti setiap satu satuan bahan bakar, 0,15 bagian merupakan hidrogen. Pada proses pembakaran sempurna, air yang dihasilkan dari pembakaran bahan bakar adalah setengah dari jumlah mol hidrogennya.

Selain berasal dari pembakaran hidrogen, uap air yang terbentuk pada proses pembakaran dapat pula berasal dari kandungan air yang memang sudah ada didalam bahan bakar (moisture). Diketahui panas laten pengkondensasian uap air pada tekanan parsial $20 \mathrm{kN} / \mathrm{m} 2$ 
(tekanan yang umum timbul pada gas buang) adalah sebesar $2400 \mathrm{~kJ} / \mathrm{kg}$, sehingga besarnya nilai kalor bawah (LHV) dapat dihitung berdasarkan persamaan berikut:

$L H V=H H V-2400\left(M+9 H_{2}\right) \ldots(3)$

Dalam perhitungan efisiensi panas dari motor bakar, dapat menggunakan nilai kalor bawah (LHV) dengan asumsi pada suhu tinggi saat gas buang meninggalkan mesin tidak terjadi pengembunan uap air. Namun dapat juga menggunakan nilai kalor atas (HHV) karena nilai tersebut umumnya lebih cepat tersedia. Peraturan pengujian berdasarkan ASME (American Society of Mechanical Enggineers) menentukan penggunaan nilai kalor atas (HHV), sedangkan peraturan SAE (Society of Automotive Engineers) menentukan penggunaan nilai kalor bawah (LHV).

Lebih lanjut, analisis biaya ditentukan dengan mengkalikan harga bahan bakar HSFO atau LSFO dengan konsumsi bahan bakar kapal.

\section{HASIL DAN PEMBAHASAN \\ 3.1 Perbandingan Daya LSFO dan HSFO}

Dengan mengetahui sifat kimia pada bahan bakar kita dapat mengetahui nilai daya pada setiap bahan bakar dengan menggunakan persamaan Dulong. Pada penelitian ini, diambil sampel bahan bakar MFO yang masuk dalam kategori HSFO pada kapal MV. SIKUD dengan spesifikasi sebagai berikut:

Tabel 3. Spesifikasi HSFO
\begin{tabular}{|c|c|c|}
\hline No & Parameter & Nilai \\
\hline 1 & Viscosity & $180 \mathrm{cSt}$ \\
\hline 2 & $\mathrm{SG}$ & 0,9601 \\
\hline 3 & $\mathrm{C}$ & $88 \%$ \\
\hline 4 & $\mathrm{H}_{2}$ & $10 \%$ \\
\hline 5 & $\mathrm{O}_{2}$ & $0,4 \%$ \\
\hline 6 & $\mathrm{~S}$ & $1 \%$ \\
\hline
\end{tabular}

Dari Tabel 3 diperoleh

$$
\begin{aligned}
\mathrm{HHV}= & 33950 \mathrm{C}+144200\left(\mathrm{H}_{2}-\mathrm{O}_{2} / 8\right) \\
& +9400 \mathrm{~S}
\end{aligned}
$$

$$
\begin{aligned}
= & 33950(88 \%)+144200(10 \%- \\
& 0,4 \%: 8)+9400(1 \%) \\
= & 44382,79 \mathrm{~kJ} / \mathrm{Kg}
\end{aligned}
$$

Setelah mendapatkan nilai kalor atas pada bahan bakar HSFO, kemudian ditentukan nilai kalor bawah (LHV) sebagai berikut :

$$
\begin{aligned}
\mathrm{LHV} & =\mathrm{HHV}-2400\left(\mathrm{M}+9 \mathrm{H}_{2}\right) \\
& =44832,79-2400(0,1 \%+9(10 \%) \\
& =44832,79-2400(0,905) \\
& =44382,79-2172 \\
& =42210,79 \mathrm{~kJ} / \mathrm{Kg}
\end{aligned}
$$

Selanjutnya, spesifikasi LSFO yang digunakan dalam penelitian ini disajikan dalam table berikut:

Tabel 4. Spesifikasi LSFO

\begin{tabular}{|c|c|c|}
\hline No & Parameter & Nilai \\
\hline 1 & $\mathrm{C}$ & $77 \%$ \\
\hline 2 & $\mathrm{H}_{2}$ & $10 \%$ \\
\hline 3 & $\mathrm{O}_{2}$ & $11 \%$ \\
\hline 4 & $\mathrm{~S}$ & $0,01 \%$ \\
\hline
\end{tabular}

Dari Tabel 4 diperoleh

$$
\begin{aligned}
\mathrm{HHV}= & 33950 \mathrm{C}+144200\left(\mathrm{H}_{2}-\mathrm{O}_{2} / 8\right)+ \\
& 9400 \mathrm{~S} \\
= & 33950(77 \%)+144200(10 \%- \\
& 11 \%: 8)+9400(0,01 \%) \\
= & 38579,69 \mathrm{~kJ} / \mathrm{Kg}
\end{aligned}
$$

Setelah mendapatkan nilai kalor atas pada bahan bakar LSFO, kemudian ditentukan nilai kalor bawah (LHV) sebagai berikut :

$$
\begin{aligned}
\mathrm{LHV} & =\mathrm{HHV}-2400\left(\mathrm{M}+9 \mathrm{H}_{2}\right) \\
& =38579,69-2400 \\
& =36179,69 \mathrm{~kJ} / \mathrm{Kg}
\end{aligned}
$$

Dari rumus dulong didapat perbandingan daya HSFO dengan LSFO, sbb. :

$44382,79 \mathrm{~kJ} / \mathrm{Kg}: 38579,69 \mathrm{~kJ} / \mathrm{Kg}$

$$
=1,15 \text { terhadap LSFO. }
$$

Jadi daya yang dihasilkan HSFO lebih besar daripada LSFO dengan rasio 1,15.

\subsection{Analisis Biaya LSFO dan HSFO}

Berdasarkan tahapan pemilihan subjek penelitian dilakukan terhadap 5 kapal dengan tipe yang berbeda dari kapal, mesin induk dan operasi pelayaran dimana kapal-kapal tersebut belum 
memasang scrubber pada saat pelaporan konsumsi bahan bakar diterima.

Tabel 5. Subjek Penelitian

\begin{tabular}{|c|c|c|l|}
\hline No & \multicolumn{1}{|c|}{ Kapal } & GRT & \multicolumn{1}{|c|}{ Tipe Mesin } \\
\hline 1 & MV. SIKUD & 7.717 & $\begin{array}{l}\text { MAKITA- MITSUI } \\
\text { MAN B\&W 3939 KW }\end{array}$ \\
\hline 2 & MT. SIMAS & 13.960 & $\begin{array}{l}\text { YICHANG MAN } \\
\text { B\&W 4900 KW }\end{array}$ \\
\hline 3 & MV. SIMSOL & 12.531 & $\begin{array}{l}\text { MAN - BMW } \\
\text { DE7S50MC 9988 kW }\end{array}$ \\
\hline 4 & MV. SIJIM & 4.632 & 8 DKM 2500 Kw \\
\hline 5 & MT. SIKUT & 33.348 & STX MAN 9480 KW \\
\hline
\end{tabular}

Diketahui harga bahan bakar HSFO tanggal 1-14 Mei 2019 sebesar Rp. 9.600.000/MT kemudian untuk LSFO sebesar Rp. 12.250.000/MT.

Harga scrubber tergantung dari besarnya mesin yang dipakai untuk investasi pembelian dan pemasangan scrubber yang mencapai US\$ 1,5 juta atau sekitar Rp. 21 miliar untuk ukuran kapal 15.000 GRT (10.000 KW) s/d 20.000 GRT (12.000 KW).

Berikut ini disajikan konsumsi bahan bakar (Fuel Oil Consumtion, FOC) MV. SIKUD selama 1 tahun.

Tabel 6. Laporan Konsumsi Bahan Bakar HSFO kapal MV. SIKUD

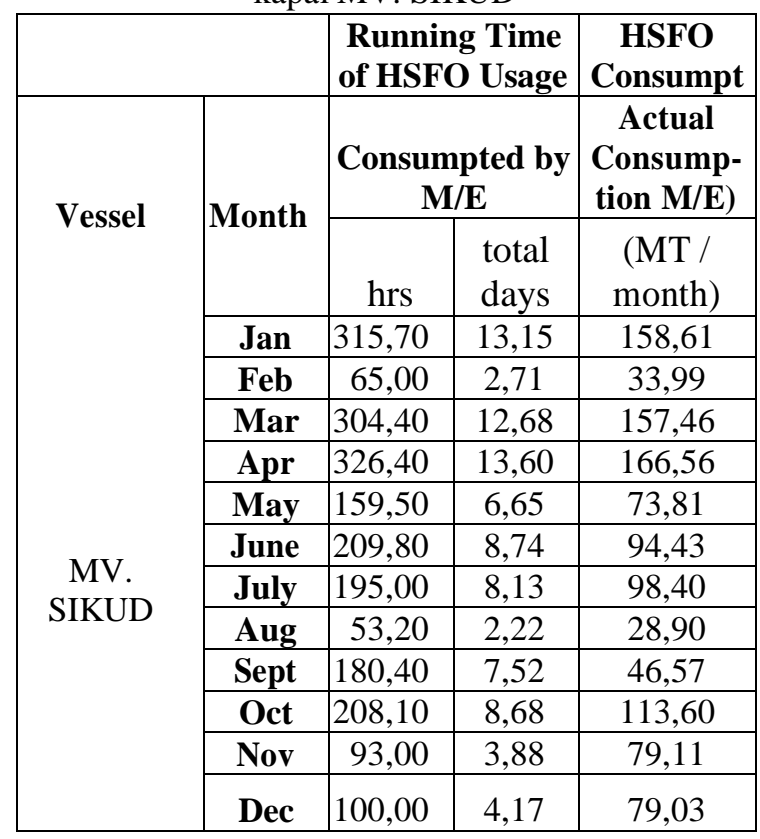

\begin{tabular}{|c|l|l|l|l|}
\hline $\begin{array}{c}\text { TOTAL } \\
\text { FOC/ } \\
\text { Tahun }\end{array}$ & & 2210,5 & 92,10 & 1130,47 \\
\hline
\end{tabular}

Biaya konsumsi bahan bakar HSFO pada MV. SIKUD untuk 1 Tahun adalah

$$
\begin{aligned}
& =1.130,47 \mathrm{MT} \times \mathrm{Rp} .9 .600 .000 / \mathrm{MT} \\
& =\text { Rp. 10.852.512.000,- }
\end{aligned}
$$

Biaya konsumsi bahan bakar LSFO pada MV. SIKUD untuk 1 Tahun apabila dengan tenaga yang sama dengan rumus Dulong adalah

$$
\begin{aligned}
= & 1.130,47 \mathrm{MT} \times 1.15 \mathrm{x} \\
& \text { Rp. } 12.250 .000 / \mathrm{MT} \\
= & \text { Rp. } 15.925 .496 .100,-
\end{aligned}
$$

Kemudian selisih pembelian HSFO dan LSFO dengan tenaga yang sama pada MV. SIKUD disajikan dalam tabel berikut ini.

Tabel 7. Selisih pembelian HSFO dan LSFO dengan tenaga yang sama pada MV. SIKUD

\begin{tabular}{|c|c|c|c|}
\hline $\begin{array}{c}\text { Harga } \\
\text { HSFO } \\
(/ M T)\end{array}$ & $\begin{array}{c}\text { FOC } \\
\text { HSFO } \\
\text { (MT/y } \\
\text { ear) }\end{array}$ & $\begin{array}{c}\text { Biaya } \\
\text { Pembelian } \\
\text { HSFO } \\
\text { (/year) }\end{array}$ & $\begin{array}{c}\text { Biaya } \\
\text { kalau } \\
\text { HSFO } \\
\text { diganti } \\
\text { LSFO }\end{array}$ \\
\hline 9.600. & 1.130, & 10.852 .51 & 15.925 .496$. \\
000 & 47 & 2.000 & 000 \\
\hline \multicolumn{3}{|c|}{ Selisih harga untuk menghasil tenaga } \\
\multicolumn{3}{|c|}{ yang sama Rp. 5.072.984.000,- } \\
\hline
\end{tabular}

Jadi selisih biaya penggunaan HSFO dan LSFO pada MV. SIKUD untuk 1 tahun adalah Rp. 5.072.984.000,-

Dari Tabel 7 dapat dianalisis bahwa penghematan yang diperoleh MV. SIKUD selama 1 tahun apabila tetap menggunakan HSFO sebesar Rp. 5.072.984.000,-. $\quad$ Namun, apabila menggunakan HSFO, shipowner akan melanggar Marpol Annex VI Regulasi 14. Oleh karena itu, Kapal MV. SIKUD harus dilengkapi dengan scrubber sehingga sulfur yang dihasilkan HSFO dapat direduksi sesuai dengan aturan yang disepakati.

Dengan melakukan investasi pembelian dan instalasi scrubber kurang lebih sebesar Rp. 10,5 Milyar, MV. SIKUD dapat menggunakan HSFO sebagai bahan bakar. Lebih lanjut, biaya 
Rp.

10,5 Milyar dapat tertutupi selama 2 tahun, apabila MV. SIKUD tetap menggunakan HSFO daripada LSFO. Jadi, pasca 2 tahun, shipowner dapat melakukan penghematan lebih banyak daripada menggunakan LSFO. Dengan menggunakan perhitungan yang sama dengan MV. SIKUD, diperoleh tabel penghematan biaya pembelian bahan bakar HSFO dibandingkan dengan LSFO sbb. :

Tabel 8. Selisih pembelian HSFO dan LSFO dengan tenaga yang sama pada MV. SIMAS

\begin{tabular}{|c|c|c|c|}
\hline $\begin{array}{c}\text { Harga } \\
\text { HSFO } \\
\text { (/MT) }\end{array}$ & $\begin{array}{c}\text { FOC } \\
\text { HSFO } \\
\text { (MT/ } \\
\text { year) }\end{array}$ & $\begin{array}{c}\text { Biaya } \\
\text { Pembelian } \\
\text { HSFO } \\
\text { (/year) }\end{array}$ & $\begin{array}{c}\text { Biaya } \\
\text { kalau } \\
\text { HSFO } \\
\text { diganti } \\
\text { LSFO }\end{array}$ \\
\hline $\begin{array}{c}9.600 . \\
000\end{array}$ & 1.734, & $\begin{array}{c}16.651 .77 \\
66\end{array}$ & $\begin{array}{c}24.435 .614 . \\
0.000\end{array}$ \\
\hline \multicolumn{3}{|c|}{ Selisih harga untuk menghasil tenaga } \\
\multicolumn{3}{|c|}{ yang sama Rp. 7.783.838.000,- } \\
\hline
\end{tabular}

Tabel 9. Selisih pembelian HSFO dan LSFO dengan tenaga yang sama pada MV. SISOL

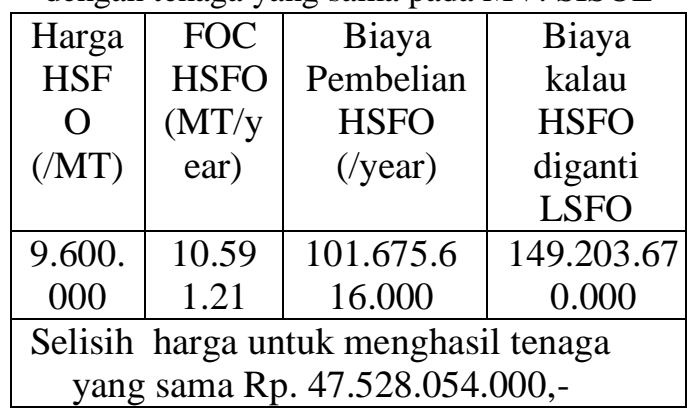

Tabel 10. Selisih pembelian HSFO dan LSFO dengan tenaga yang sama pada MV. SIJIM

\begin{tabular}{|c|c|c|c|}
\hline $\begin{array}{c}\text { Harga } \\
\text { HSF }\end{array}$ & $\begin{array}{c}\text { FOC } \\
\text { HSFO } \\
\text { (MT/ }\end{array}$ & $\begin{array}{c}\text { Bembelian } \\
\text { HSFO } \\
\text { (/year) }\end{array}$ & $\begin{array}{c}\text { Biaya } \\
\text { kalau } \\
\text { ySFO } \\
\text { diganti } \\
\text { LSFO }\end{array}$ \\
\hline 9.600 & 19.95 & 191.531. & $\begin{array}{c}281.062 .67 \\
0.000\end{array}$ \\
.000 & 1.21 & 616.000 & 0.000 \\
\hline Selisih harga untuk menghasil tenaga \\
\multicolumn{4}{|c|}{ yang sama Rp. 89.531.054.000,- } \\
\hline
\end{tabular}

Tabel 11. Selisih pembelian HSFO dan LSFO dengan tenaga yang sama pada MV. SIKUT

\begin{tabular}{|c|c|c|c|}
\hline Harga & FOC & Biaya & Biaya \\
HSF & HSFO & Pembelian & kalau \\
O & (MT/ & HSFO & HSFO \\
(/MT) & year) & (/year) & diganti \\
& & & LSFO \\
\hline
\end{tabular}

https://10.46484/db.v1i1.179

\begin{tabular}{|c|c|c|c|}
\hline $\begin{array}{c}9.600 \\
.000\end{array}$ & $\begin{array}{c}59.48 \\
0,53\end{array}$ & $\begin{array}{c}571.013 . \\
088.000\end{array}$ & $\begin{array}{c}837.931 .96 \\
6.000\end{array}$ \\
\hline & & er & $\begin{array}{l}\text { enaga } \\
00,-\end{array}$ \\
\hline
\end{tabular}

Dari Tabel 7 s.d 11 diperoleh analisis sebagai berikut:

1. Dengan melakukan Capital Expenditure (CapEx) untuk pembelian exhaust gas cleaning system atau scrubber dengan tetap memakai HSFO dengan dideprisiasi investasi 10 tahun, maka penggunaan scrubber akan lebih menguntungkan dibandingkan harus diganti menggunakan LSFO.

2. Investasi diperkirakan untuk kapal yang sedikit jumlah hari operasinya maka return of investation (ROI) hanya 1 Tahun dan selebihnya adalah keuntungan atas pembelian dan instalasi scrubber.

3. Untuk kapal yang tingkat operasi tinggi maka ROI nya dalam pembelian dan instalasi scrubber hanya 3 bulan saja.

4. Dalam pemikiran peneliti bahwa secara total Capital Expenditure $(\mathrm{CapEx})+$ Operation Expenditure $(\mathrm{OpEx})+$ Maintenance untuk scrubber sangat menguntungkan terutama kapal dengan HSFO yang beroperasi secara maksimal seperti table 7 s.d 11.

\section{SIMPULAN}

Dari hasil penelitian ini, diperoleh kesimpulan bahwa daya yang dihasilkan HSFO lebih besar daripada LSFO dengan rasio 1,15. Kemudian, shipowner akan mendapat keuntungan yang lebih banyak apabila melakukan investasi pembelian dan instalasi scrubber pada kapal-kapal mereka daripada mengganti bahan bakar yang semula HSFO dengan LSFO.

\section{DAFTAR PUSTAKA}


Alvik S, Eide M.S, Endresen $\varnothing$, Hoffmann P, Longva T. (2010) Pathways to Low Carbon Shipping-Abatement Potential Towards 2030, DNV, Editor. Høvik.

American Berau Sociaty (ABS) MARPOL Annex VI: Energy Efficiency Regulations \& Overview of ISO 50001

Buhaug., Corbett, J.J., Endresen., Eyring, V., Faber, J, (2009). Second IMO GHG Study 2009. International Maritime Organization (IMO), London, UK.

Faber, J. et al, (2009). Technical Support for European Action to Reducing Greenhouse Gas Emissions from International Maritime Transport. CE Delft, NY, pp.353.

Gilbert, P. (2014). From reductionism to systems thinking: how the shipping sector can address sulphur regulation and tackle climate change. Marine Policy 43, 376-378.

Helfre J.F., Boot P.A.C., (2013). Emission reduction in the shipping industry:regulations, exposure and solutions, Sustainlytics.

Habibi, M., \& Rehmatulla, N. (2009). Carbon emission policies in the context of the shipping industry. CASS Business School: City University, London.

Marine Pollution (Marpol) Convention Annex VI Regulasi 14 (IMO)
Napitulu, F., H., Pengaruh Nilai Kalor (Heating Value) suatu bahan bakar terhadap perencanaan volume ruang bakar ketel uap berdasarkan metode penentuan nilai kalor bahan bakar yang digunakan. Jurnal Sistem Teknik Industri, Vol. 7, No. 1, Januari 2006, pp. 60-65.

Sudiono, Kandungan Sulfur di Bahan Bakar Laut akan dibatasi 0.5\%, DetikNews, Hari Selasa, Tgl 30 Juli 2019. https://news.detik.com/berita/d -4645684/kandungan-sulfur-dibahan-bakar-kapal-laut-akandibatasi-05\#, diakses 9 Oktober 2019.

Simanjuntak, M., Malau, A. G., Kalangie, T. J. F., \& Sukmanofith, D. (2019). Kajian Tingkat Kebutuhan Kompetensi Berdasarkan Permenhub No. PM 7 Tahun 2018 Tentang Rencana Induk Pengembangan SKKNI Sektor Transportasi. Meteor STIP Marunda, 12(1), 1-14.

Sadjiono, I., \& Malisan, J. (2019). Analisa Keselamatan Transportasi Angkutan Penyeberangan Bira-Pamatata: Studi Kasus Tenggelamnya Kapal Ferry KM. Lestari Maju. Meteor STIP Marunda, 12(1), 25-34. 